\section{Yet Another Crisis}

Dear Reader,

at the moment, we seem to be moving straight from one crisis to the next. First, the production lines came to a stop because of the coronavirus pandemic, which meant that fewer semiconductors were ordered. Then a ship blocked one of the most important shipping routes in the world. And now we've discovered that an industry which is just starting up again cannot deliver as many parts as are needed immediately and definitely not when the production site is on the other side of the world.

In crisis number one it became clear that our supply chains are too long, but nothing changed. In crisis number two we realized that having only a limited number of transport routes presents a problem. Once again nothing changed. And now everyone wants to order at the same time - the quantity of parts that they canceled orders for during the first crisis or more and they want them delivered immediately. It is not really a surprise that this is not working, but once again that is only part of the problem. In recent years, keeping large stocks of parts has been frowned on and just-in-time production has become the holy grail of an efficient industry. Even the most enthusiastic supporters of this type of system were aware that just one bottleneck could bring production to a standstill, but its most vehement critics probably did not suspect that things could go wrong in three areas at once.

And now something that no one wanted is happening, for the third time. A tiny component is shutting down production lines and even resulting in the closure of entire plants. As we all know, stopgap solutions generally work better than expected. This is why the concern about whether the factories will come to a permanent standstill, even after the crisis is over, is fully justified.

Our industry simply has to put up with people pointing out that the crises were home-made, that the consequences were predictable and that no one really has the right to complain. And now when several events have occurred one after another that everyone said were unlikely, it is finally time for us to revise our concepts. The transformation is already in full swing, so this is the ideal opportunity.

I hope you enjoy this issue of MTZ.

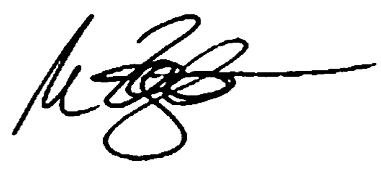

Marc Ziegler

Deputy Editor in Chief

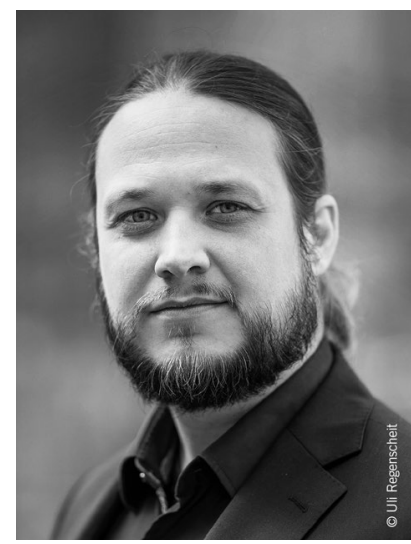

\section{DRIVE. EFFICIENCY. POWER.}

The automotive industry is facing new challenges - the turnaround in mobility requires consistent rethinking and technology-neutral development. As a leading international technical and scientific magazine for decision-makers working in drive development and production, MTZworldwide sees itself as an information platform on future drive systems - electric and internalcombustion-engine-based. MTZworldwide promotes the exchange of information between manufacturers, suppliers, service providers, and R\&D centers worldwide. Take advantage of the interactive e-magazine and benefit from the extensive information in our unique online archive, which gives you the option of downloading PDF files.
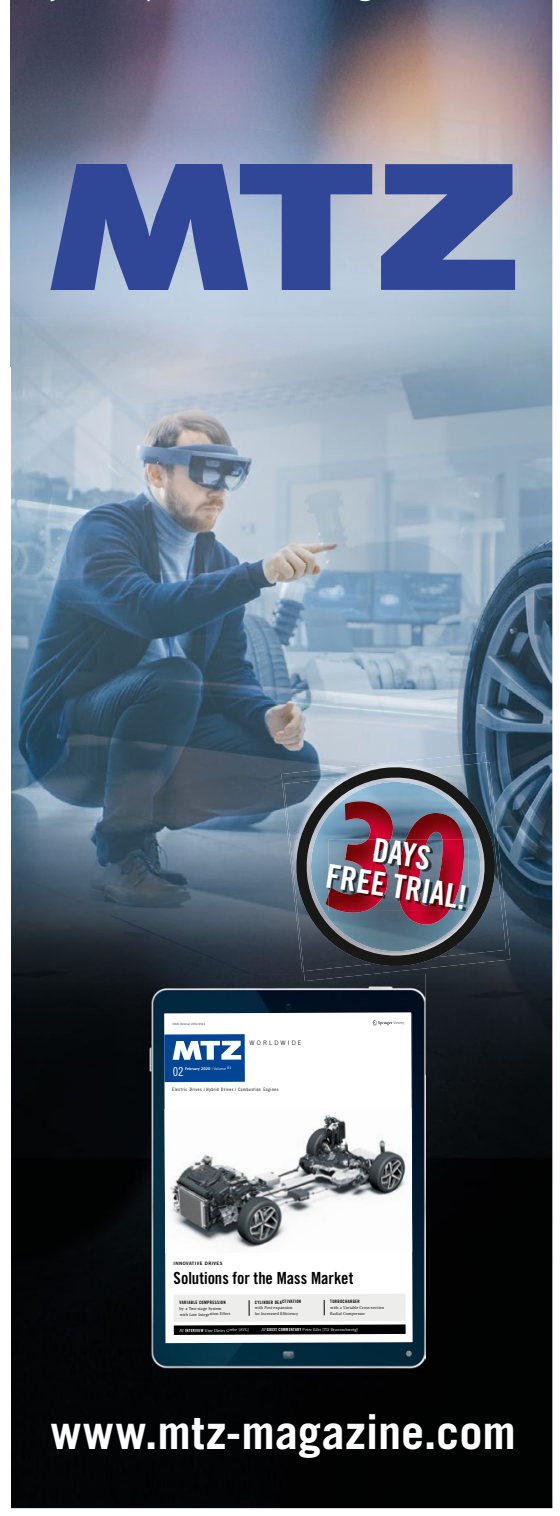